\author{
ПОВЕРХНОСТНО-ВОЛНОВАЯ ТОМОГРАФИЯ АРКТИКИ \\ ПО ДАННЫМ ДИСПЕРСИИ ГРУППОВЫХ СКОРОСТЕЙ ВОЛН \\ РЭЛЕЯ И ЛЯВА \\ (C) 2019 г. А. И. Середкина \\ Институт земной коры СО РАН, г. Иркутск \\ Институт земного магнетизма, ионосферы и распространения радиоволн \\ им. Н.В. Пушкова РАН, г. Москва, г. Троицк, Россия \\ E-mail:ale@crust.irk.ru \\ Поступила в редакцию 11.12.2017 г. \\ Принята в печать 28.05.2018 г.
}

\begin{abstract}
В работе представлены результаты исследования глубинного строения земной коры и верхней мантии Арктики по данным поверхностных волн. Для этого с помощью метода спектральновременного анализа была получена представительная выборка дисперсионных кривых групповых скоростей волн Рэлея (1555 трасс) и Лява (1265 трасс) в диапазоне периодов колебаний $10-250$ с. Методом двумерной томографии для случая сферической поверхности рассчитаны распределения групповых скоростей на отдельных периодах. Всего построено по 18 карт для каждого типа поверхностных волн и сделаны оценки горизонтального разрешения результатов картирования. Для четырех различных в тектоническом отношении регионов Арктики проведена инверсия дисперсионных кривых, вычисленных по результатам томографии, в скоростные разрезы волн $S V$ и $S H$. Полученные распределения позволили проанализировать основные крупномасштабные особенности глубинного строения земной коры и верхней мантии Арктики, а также связать выявленные скоростные неоднородности с различными геологическими структурами. Результаты проведенного исследования представляют существенный интерес для дальнейшего построения трехмерной модели распределения скоростей поперечных волн и изучения анизотропных свойств верхней мантии Арктики, а также для построения геодинамических моделей рассматриваемого региона.
\end{abstract}

Ключевые слова: поверхностно-волновая томография, групповые скорости, волны Рэлея и Лява, верхняя мантия, Арктика

DOI: https://doi.org/10.31857/S0002-33372019358-70

\section{ВВЕДЕНИЕ}

Арктический регион состоит из различных в геологическом и тектоническом отношении структур (рис. 1). Его континентальная часть представлена древними платформами и щитами, а также более молодыми складчатыми поясами Евразии и Северной Америки [Зоненшайн, Натапов, 1987; Зоненшайн и др., 1990]. Океаническая часть области исследования включает в себя шельфы окраинных морей, глубоководные океанические бассейны с разделяющими их поднятиями Ломоносова, Альфа-Менделеева и спрединговым хребтом Гаккеля с ультрамедленными скоростями раздвижения, изменяющимися в пределах от $0.6 \mathrm{~cm} /$ год на востоке до $1.3 \mathrm{~cm} /$ год на западе [DeMets et al., 1994].
В настоящее время в Арктике ведется активная разработка и добыча полезных ископаемых, в том числе углеводородов, залегающих на российском шельфе. Развитие хозяйственной деятельности, в свою очередь, требует детальных оценок сейсмической опасности территории. Для более точного проведения последних, а также для решения многих спорных вопросов современной тектоники и геодинамики, большой интерес представляют новые данные о глубинном строении.

Недостаток сейсмических станций и неравномерность распределения эпицентров землетрясений в высоких северных широтах накладывают существенные ограничения на исследования глубинного строения земной коры и верхней 

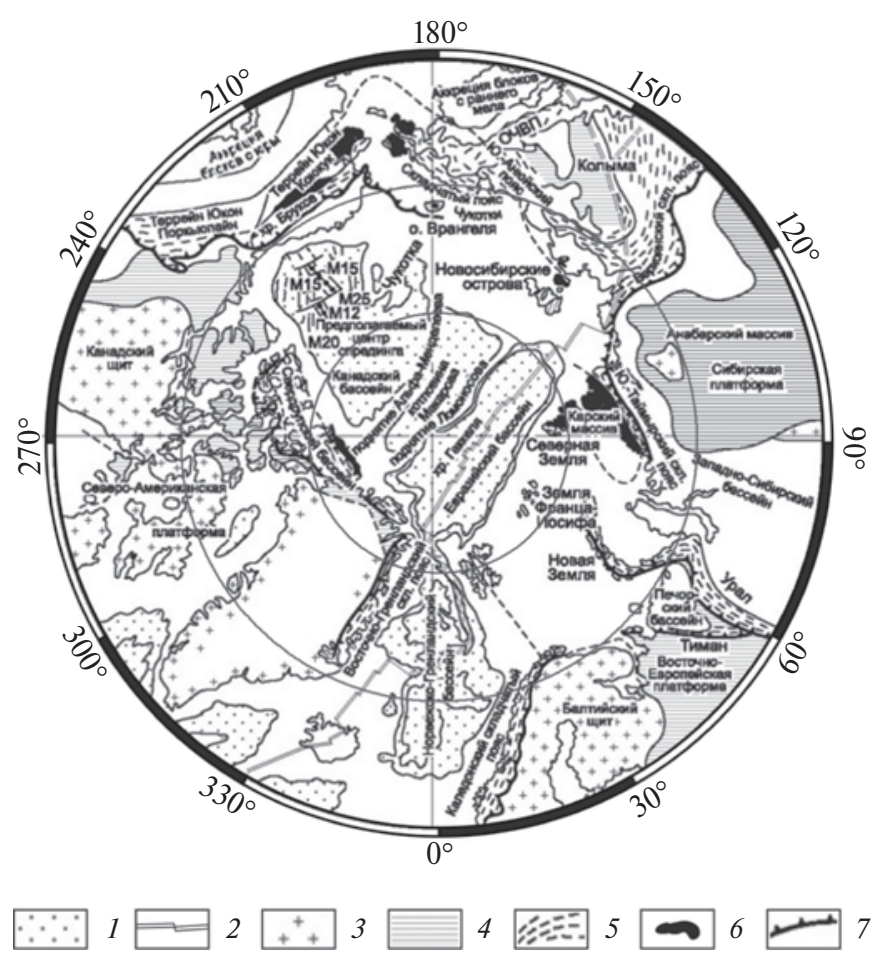

Рис. 1. Главные геологические структуры Арктики по работе [Зоненшайн, Натапов, 1987]: 1 - океанические бассейны глубже 2000 м, нанесены изобаты 2000 и 3000 м; 2 - активный спрединговый центр; 3-5 - континентальные структуры (3 - щиты; 4 платформы; 5 - орогенические пояса); 6 - древние массивы, остатки континента Арктида; 7 - фронт складчатости; М12, М15, М20, М25 - мезозойские магнитные аномалии.

мантии Арктики. Обзор существующих моделей глубинного строения приведен в работе [Gaina et al., 2014]. Следует отметить, что основная имеющаяся на данный момент информация о рассматриваемом регионе содержится в глобальных моделях [Bijwaard et al., 1998; Shapiro, Ritzwoller, 2002; Zhou et al., 2006; Ekström, 2011; Laske et al., 2013; Schaeffer, Lebedev, 2013; и др.]. Однако для Арктики они характеризуются достаточно низким разрешением по сравнению с другими областями Земли. Не лишены схожих проблем с разрешением и немногочисленные региональные исследования [Levshin et al., 2001; Яковлев и др., 2012], в то время как результаты более детальных работ, основанных на данных объемных [Allen et al., 2002; Darbyshire, 2003; Kumar et al., 2005; Lebedeva-Ivanova et al., 2006; Jokat, Schmidt-Aursch, 2007; и др.] и поверхностных волн [Bruneton et al., 2004; Darbyshire et al., 2004; Pilidou et al., 2004; 2005; Levshin et al., 2007; Chen et al., 2007; Pedersen et al., 2013], имеют весьма локальный характер. Таким образом, целью данной работы является исследование глубинного строения Арктики методом поверхностно-волновой томографии путем построения карт распределений групповых скоростей волн Рэлея и Лява в диапазоне периодов 10-250 с и их последующей интерпретации.

\section{ИСХОДНЫЕ ДАННЫЕ И МЕТОДЫ ИССЛЕДОВАНИЯ}

Материалом для исследования служили записи поверхностных волн от удаленных землетрясений на каналах LHZ и LHT цифровых широкополосных сейсмических станций сетей IRIS, GEOSCOPE, GEOFON и относительно недавно установленной в Гренландии сети GLISN (рис. 2a). Всего было использовано 38 землетрясений $\left(M_{\mathrm{w}} \geq 5.1,1996-2015\right.$ гг.), произошедших (a)

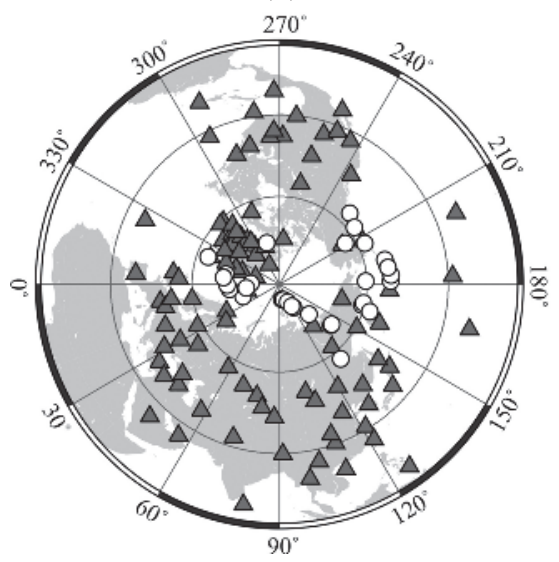

(б)

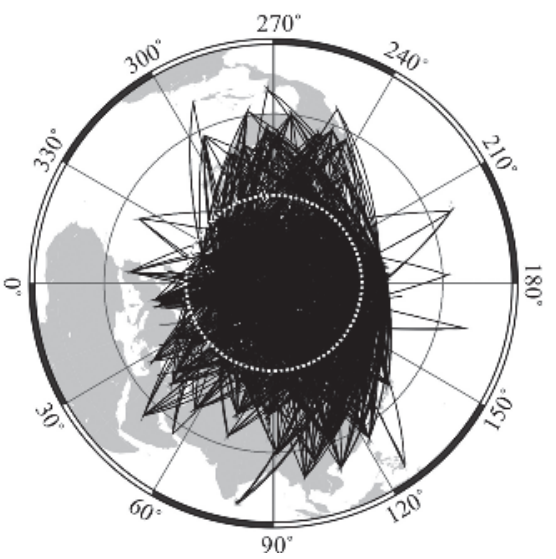

(B)

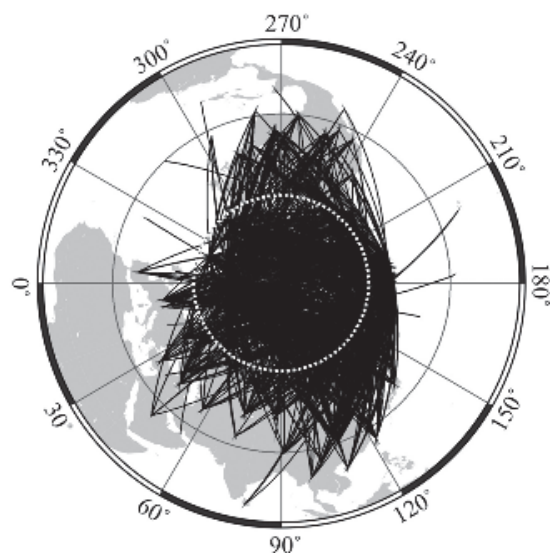

Рис. 2. Положение эпицентров выбранных для анализа землетрясений (кружки) и сейсмических станций (треугольники) (а), полученные сейсмические трассы для волн Рэлея (б) и Лява (в). 
в Исландии, вблизи Гренландии, на Аляске и северо-востоке Евразии, вдоль хребта Гаккеля и Алеутской дуги (рис. 2a). Дисперсионные кривые групповых скоростей рассчитывались вдоль трасс «эпицентр - станция». Диапазон расстояний от эпицентров выбранных для анализа землетрясений до регистрирующих станций составил 2000-10000 км. В большинстве случаев это позволило выделить основную моду поверхностных волн в пределах диапазона периодов колебаний от 10 до 250 с, что, согласно [Ritzwoller, Levshin, 1998; Яновская, 2015], соответствует глубинности около 500 км.

Дисперсионные кривые групповых скоростей фундаментальных мод поверхностных волн рассчитывались с помощью процедуры спектрально-временного анализа (CBAH) [Левшин и др., 1986]. Для анализа использовались только записи с высоким отношением сигнал/шум.
На рис. 3 показан пример обработки землетрясения 6 марта 2005 г. $\left(M_{\mathrm{w}}=6.3\right)$, произошедшего на хребте Гаккеля, на станции Ала-Арча (ААК). Всего, таким образом, было получено 1555 дисперсионных кривых для волн Рэлея (рис. 2б) и 1265 - для волн Лява (рис. 2в).

Оценка ошибок определения значений групповых скоростей осуществлялась по воспроизводимости дисперсионных кривых: дисперсионные кривые для близких трасс усреднялись и вычислялись среднеквадратичные отклонения (CKO) скоростей на отдельных периодах от их средних значений. Средние для исследуемого региона дисперсионные кривые для волн Рэлея и Лява с погрешностями приведены на рис. 4, из которого видно, что наименьшие значения СКО приурочены к интервалу T $=25-150$ с, а на остальных периодах СКО несколько выше. На малых периодах $(\mathrm{T}<25$ c) большой разброс (a)
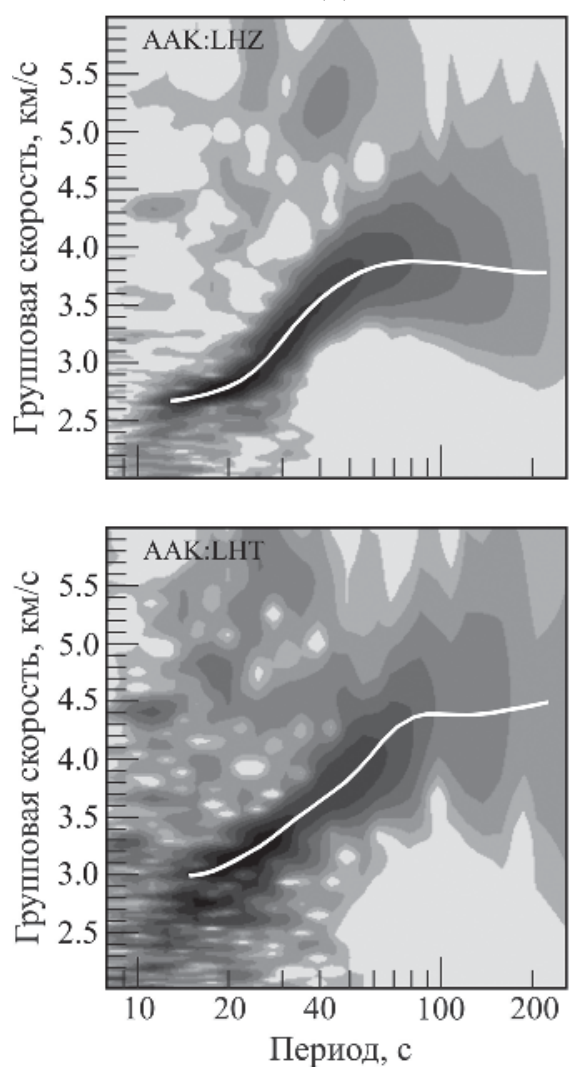

(б)
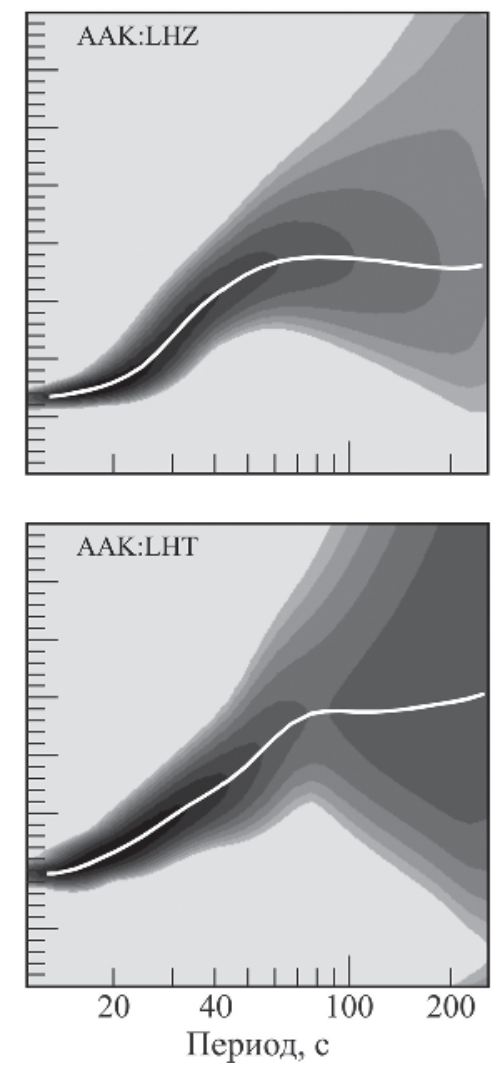

(B)
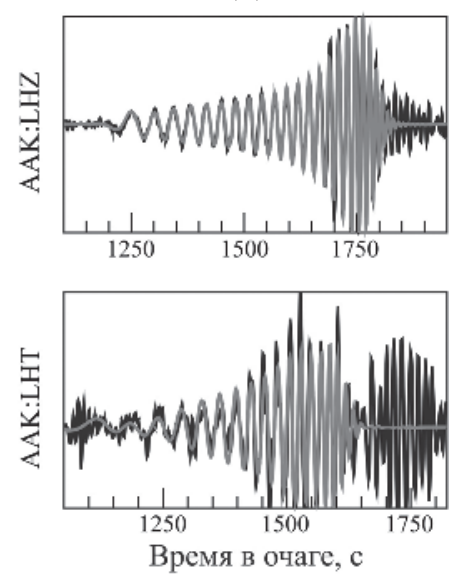

(г)

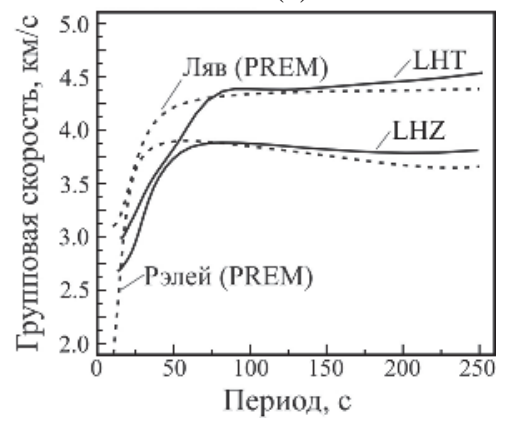

Рис. 3. Пример обработки землетрясения 6 марта 2005 г. $\left(M_{\mathrm{w}}=6.3\right)$, записанного на вертикальной (LHZ) и трансверсальной (LHT) компонентах станции AАK ( $\Delta=4775$ км): СВАН-диаграммы исходного (а) и отфильтрованного (б) сигналов (дисперсионная кривая групповой скорости обозначена белым цветом); (в) - сейсмограммы до (черные кривые) и после (серые кривые) фильтрации; (г) - полученные дисперсионные кривые групповых скоростей в сравнении с дисперсионными кривыми, рассчитанными для модели PREM [Dziewonski, Andersen, 1981]. 


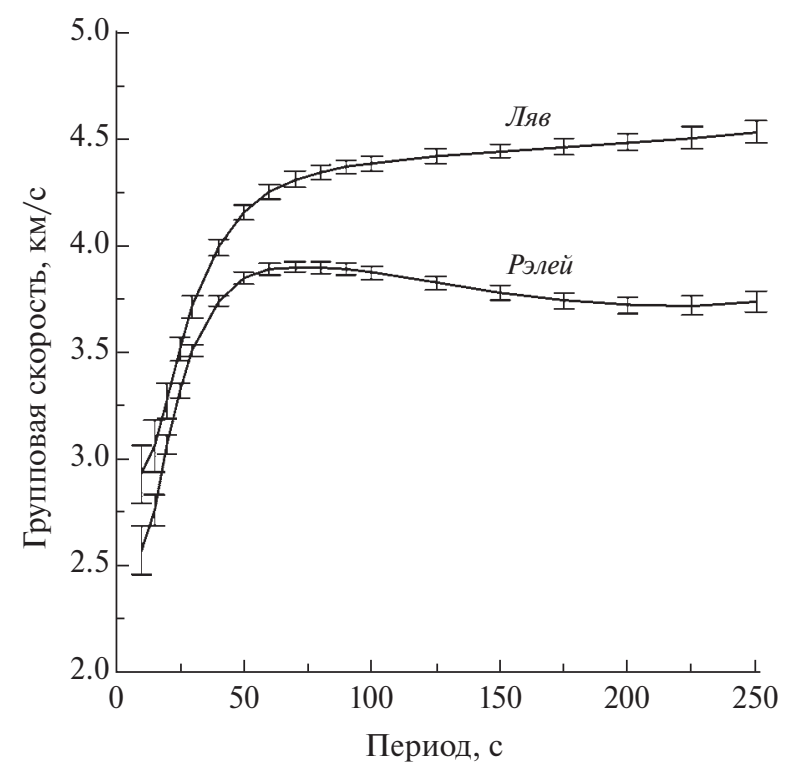

Рис. 4. Средние для рассматриваемого региона дисперсионные кривые волн Рэлея и Лява с оценками погрешностей определения групповых скоростей.

в значениях групповых скоростей может быть обусловлен не только ошибками вычислений, но и высокой степенью неоднородности земной коры, особенно ее верхней части. Также следует отметить худшую воспроизводимость дисперсионных кривых для волн Лява. В целом, полученные результаты согласуются с данными [Ritzwoller, Levshin, 1998].

Карты распределений групповых скоростей были рассчитаны методом двумерной томографии для случая сферической поверхности [Yanovskaya et al., 2000; Яновская, 2001; 2015]. Для каждой из карт были сделаны оценки разрешения результатов картирования путем вычисления эффективного радиуса осреднения $(R)$ [Яновская, 2001; 2015; Yanovskaya, Kozhevnikov, 2003], который зависит, главным образом, от плотности покрытия того или иного участка области исследования сейсмическими трассами. Проведенные ранее синтетические тесты показали [Яновская, 2015], что значения радиуса эквивалентной области сглаживания хорошо согласуются с результатами, полученными методом «шахматной доски». В нашем случае наилучшим разрешением (400-600 км для волн Рэлея и 500-700 км для волн Лява) характеризуется центральная часть области исследования (севернее $70^{\circ}$ с. ш.), а также северо-восток Евразии и Аляска (рис. 5). На периферии, особенно в южной Гренландии и Канаде, эффективный радиус осреднения принимает более высокие значения. Кроме того, горизонтальное разрешение закономерно ухудшается с увеличением периода в связи с уменьшением количества сейсмических трасс, используемых для анализа. В качестве границы приемлемого разрешения принято $R=1000$ км аналогично [Yanovskaya, Kozhevnikov, 2003].

Анализ карт распределений групповых скоростей для отдельных периодов позволяет получить общие представления о крупномасштабных горизонтальных неоднородностях верхней мантии Арктики. Для того чтобы на качественном уровне оценить глубинность выявленных скоростных аномалий для четырех различных в тектоническом отношении регионов было проведено обращение локальных дисперсионных кривых волн Рэлея и Лява, полученных по результатам томографии, в скоростные разрезы $S$-волн.

Расчет параметров моделей среды, удовлетворяющих локальным дисперсионным кривым, осуществлялся с помощью минимизации невязок между теоретическими и экспериментальными значениями групповых скоростей методом сопряженных градиентов [Яновская, 2015]. В качестве исходной была принята модель среды с 2 плоскопараллельными слоями коры и 11 слоями мантии с линейным изменением скорости с глубиной на полупространстве. Варьируемыми параметрами служили скорости поперечных волн в слоях коры и мантии и мощности слоев коры. В качестве начального приближения для коры использовались модели EUNA [Artemieva, Thybo, 2013] и CRUST 1.0 [Laske et al., 2013], для мантии - сферически симметричная модель PREM [Dziewonski, Anderson, 1981]. Вначале по данным групповых скоростей волн Рэлея рассчитывались скоростные разрезы волн $S V$. Затем они использовались в качестве начальных моделей при построении скоростных разрезов волн $S H$, удовлетворяющих дисперсионным кривым волн Лява. Для проверки устойчивости полученных результатов строился усредненный по этим двум решениям разрез, от которого снова проводились расчеты для обоих типов поверхностных волн. Во всех случаях полученные таким образом скоростные разрезы практически совпадали с результатами первоначальных вычислений. 
(a)
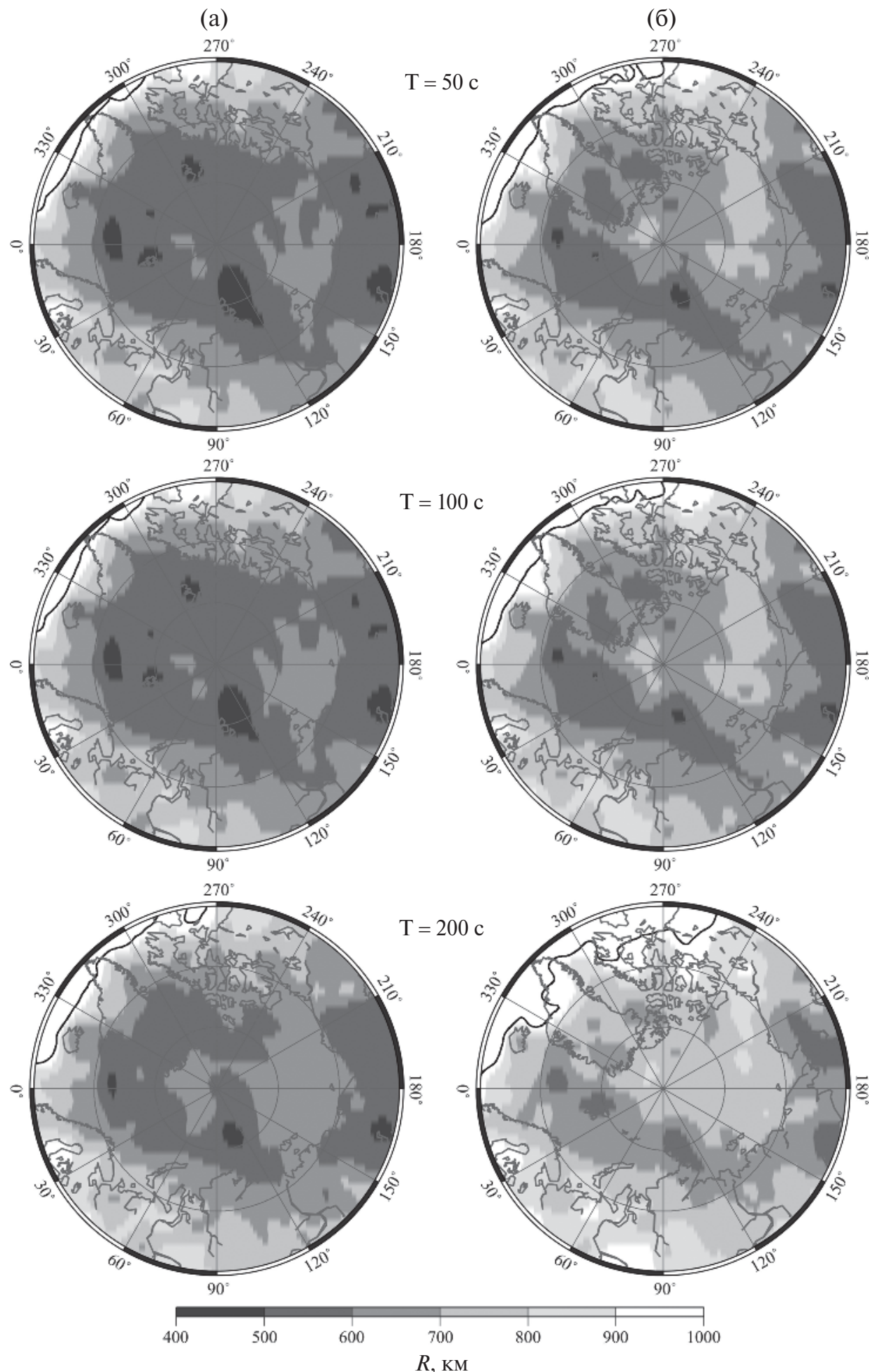

Рис. 5. Примеры карт эффективного радиуса осреднения $(R$, км) для волн Рэлея (а) и Лява (б) для периодов колебаний 50,100 и 200 с. Граница $R=1000$ км обозначена черной кривой. 


\section{РЕЗУЛЬТАТЫ ИССЛЕДОВАНИЯ И ИХ ОБСУЖДЕНИЕ}

В соответствии с используемой методикой распределения групповых скоростей рассчитывались отдельно для каждого периода колебаний. Для интервалов периодов 10-30, 30-100, 100-250 с шаг по периоду составил 5, 10 и 25 с, соответственно. Таким образом, было построено по 18 карт для каждого типа поверхностных волн. При интерпретации полученных карт и сопоставлении вариаций групповых скоростей с геологическим строением исследуемой области (рис. 1) необходимо иметь в виду, что волны Рэлея и Лява характеризуются различной чувствительностью к параметрам среды и различной проникающей способностью [Яновская, 2015].

Для обоих типов поверхностных волн карты для периода 20 с (рис. 6) отражают особенности строения земной коры, а вариации групповых скоростей изменяются в широких пределах: от -20 до $+20 \%$. Минимумы групповых скоростей на этих картах приурочены к бассейнам окраинных морей и к крупным осадочным бассейнам на севере Евразии: Енисейско-Хатангскому и Лено-Анабарскому [Drachev, 2016]. Причем интенсивность выявленных минимумов коррелирует с мощностью осадочных отложений [Gramberg et al., 1999]. Бассейны Северного Ледовитого океана и глубоководных Гренландского и Норвежского морей характеризуются высокими значениями скоростей поверхностных волн, что, вероятно, обусловлено утонением коры под данными областями [Laske et al., 2013; Artemieva, Thybo, 2013]. Характер дисперсии для периода колебаний 50 с (рис. 7, рис. 8) для континентальной части области исследования определяется как влиянием коры, так и верхней части мантии, и, в определенной мере, отражает вариации мощности коры под различными регионами.

Карты для более высоких периодов колебаний (до 150 с) отражают распределение горизонтальных неоднородностей в мантийной части литосферы и в астеносфере, а для периодов более 150 с на характер дисперсии скоростей поверхностных волн оказывают влияние подастеносферные слои верхней мантии и нижняя мантия. Максимальные значения вариаций групповых скоростей (до +5\%) на этих периодах приурочены к Канадскому и Балтийским щитам, что свидетельствует о большой мощности литосферы (до 280 км) и высоких скоростях поперечных волн в ней [Chen et al., 2007; Olsson et al., 2007; Darbyshire et al., 2013; Grad et al., 2014]. Также повышенными значениями скоростей $(+1 \ldots+3 \%)$ характеризуются Восточно-Европейская и Сибирская платформы, причем под последней с увеличением периода данная особенность становится более выраженной. Минимальные значения скоростей (до -10\%) приурочены к складчатым поясам северо-востока (a)

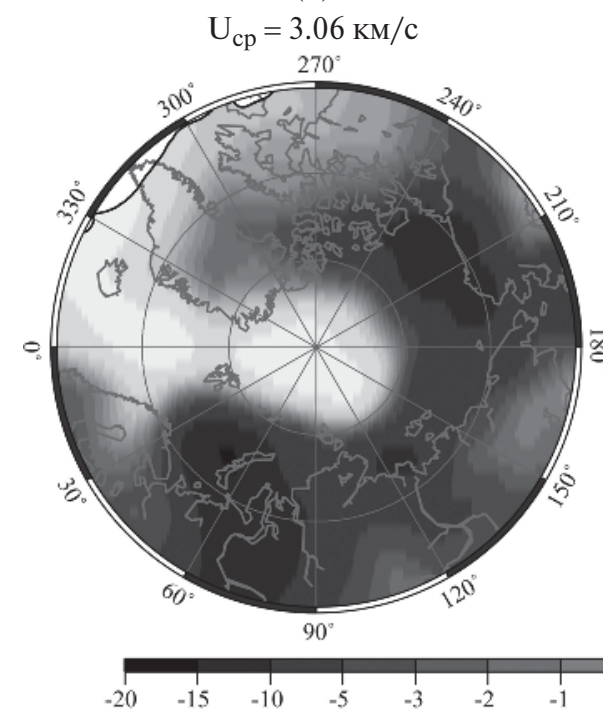

(б)

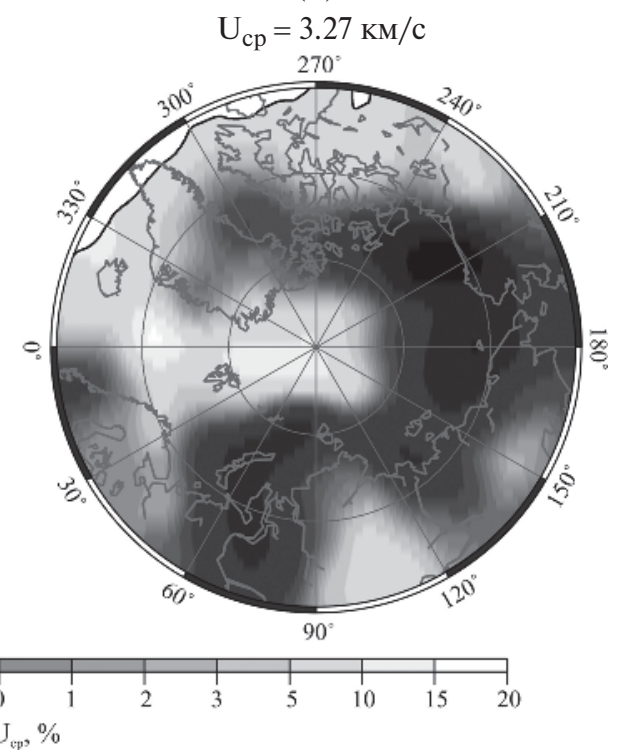

Рис. 6. Вариации групповых скоростей волн Рэлея (а) и Лява (б) относительно средних значений $\left(\mathrm{U}_{\mathrm{cp}}\right)$ для периода колебаний 20 с. 

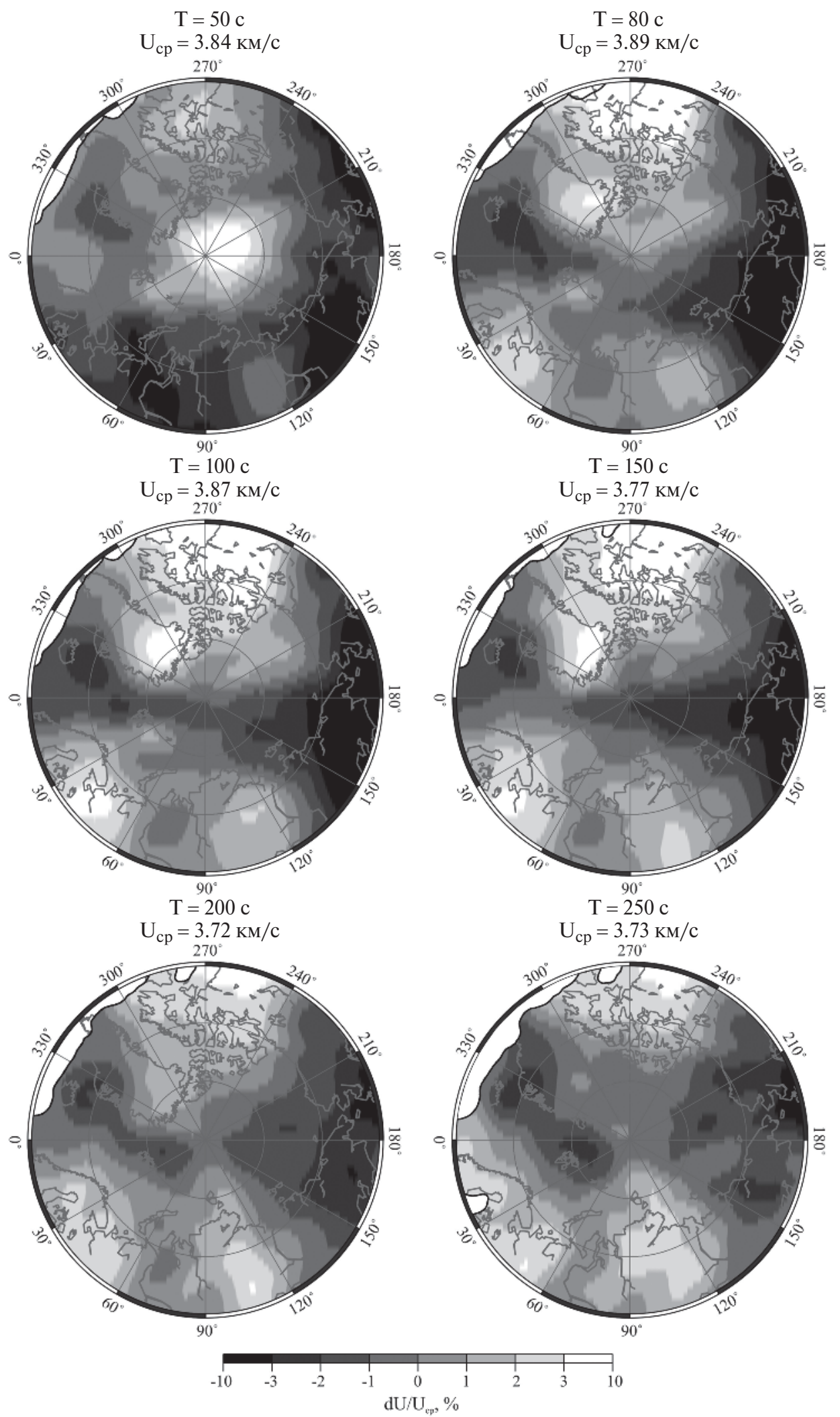

Рис. 7. Вариации групповых скоростей волн Рэлея относительно средних значений $\left(\mathrm{U}_{\mathrm{cp}}\right)$ для периодов колебаний $50,80,100,150,200$ и 250 с. 

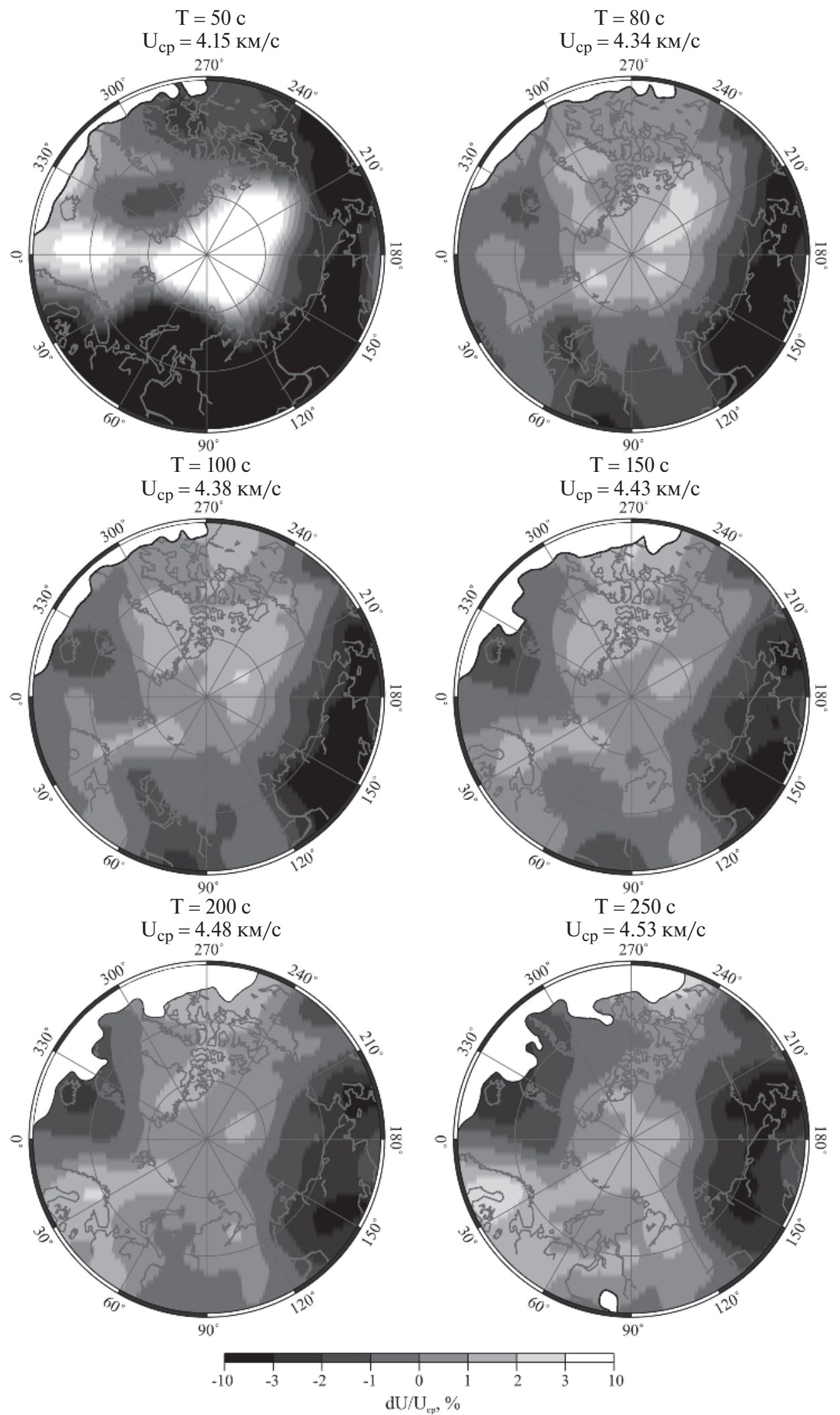

Рис. 8. Вариации групповых скоростей волн Лява относительно средних значений $\left(\mathrm{U}_{\mathrm{cp}}\right)$ для периодов колебаний $50,80,100,150,200$ и 250 с. 
Евразии и Аляски, а также к бассейну Берингова моря, где происходит современная субдукция Тихоокеанской плиты.

Выявленные тенденции наглядно проявлены в скоростных разрезах $S$-волн, рассчитанных для четырех различных в тектоническом отношении структур исследуемой области: океанической котловины Амундсена, Балтийского щита, шельфа Баренцева моря и Верхояно-Колымского складчатого пояса (рис. 9). На периодах до 60 с для волн Рэлея и до 80 с для волн Лява наиболее высокие групповые скорости наблюдаются в глубоководной котловине Амундсена (рис. 9а), обладающей утоненной корой океанического типа [Laske et al., 2013; Gaina et al., 2014], что также проявлено в максимальных скоростях $S$-волн до глубин около 50 км относительно остальных рассматриваемых регионов (рис. 9б). С увеличением периода, как и предполагалось, максимальные значения как групповых скоростей, так и скоростей поперечных волн, прослеживаются под стабильным докембрийским Балтийским щитом. Следует отметить, что полученный скоростной разрез волн $S V$ хорошо согласуется с результатами, вычисленными по данным о дисперсии фазовых скоростей волн Рэлея на группе станций LAPNET [Pedersen et al., 2013]. Так, в обеих моделях значения скоростей волн $S V$ в интервале глубин 50-250 км составляют 4.5-4.6 Kм/с с максимумом на глубине около 150 км и небольшим понижением в диапазоне 160-220 км (рис. 9б). Относительно высокие скорости поперечных волн $(>4.5 \mathrm{~km} / \mathrm{c})$ наблюдаются в верхней мантии Баренцева моря. В предыдущих исследованиях этого региона по групповым и фазовым скоростям поверхностных волн [Levshin et al., 2007], где в качестве примера инверсии рассмотрена точка с теми же координатами $\left(74^{\circ} \mathrm{N}, 40^{\circ} \mathrm{E}\right)$, характер скоростного разреза волн $S H$ (максимум на 60-80 км и плавное понижение скоростей до 200 км), а также абсолютные значения групповых скоростей волн Рэлея и Лява, практически совпадают с результатами данной работы. Некоторая несогласованность скоростных разрезов волн $S V$ в интервале глубин 50-100 км, вероятнее всего, обусловлена различной разрешающей способностью исходных данных. Минимальными значениями скоростей $S$-волн для рассматриваемых структур характеризуется верхняя мантия Верхояно-Колымского складчатого пояса, что также находит свое отражение в дисперсии групповых скоростей поверхностных волн (рис. 7, рис. 8, рис. 9а) и не противоречит результатам предшествующих исследований по данным поверхностных [Levshin et al., 2001], объемных волн [Яковлев и др., 2012] и их совместной инверсии [Schaeffer, Lebedev, 2013].

На периодах от 50 и до 250 с на картах для обоих типов поверхностных волн наблюдается локальный минимум скоростей $(-3 \%)$ в районе Исландии, скорее всего, связанный с Исландским мантийным плюмом, глубинность которого оценивается от 200 [Pilidou et al., 2004; 2005] до 400 [Bijwaard et al., 1998] и даже до 700 км [Яковлев и др., 2012]. Данная аномалия прослеживается на сотни километров к северу от Исландии, что согласуется с результатами предыдущих исследований [Levshin et al., 2001; Pilidou et al., 2004; 2005] и может свидетельствовать также о наличии плюма под островом Ян-Майен. Последний выделяется как по геологическим данным [Schilling et al., 1999], так и по результатам региональной томографии с более высоким горизонтальным разрешением [Rickers et al., 2013].

На картах для волн Рэлея (рис. 7) хребет Гаккеля на периодах до 200 с прослеживается в виде минимума групповых скоростей. Примечательно, что при переходе из Евразийского бассейна в пределы континентальной окраины моря Лаптевых довольно узкая зона спрединга расширяется, превращаясь в систему рифтовых впадин, что проявляется в смене характера сейсмичности [Avetisov, 1999; Имаева и др., 2017] и различных геофизических полях [Verhoev et al., 1996; Kenyon et al., 2008; Andersen et al., 2010], в том числе и в расширении зоны пониженных групповых скоростей на шельфе, полученном в данной работе. Другой интересной особенностью является то, что с увеличением периода (более 200 с) на картах для волн Лява (рис. 8) под хребтом Гаккеля наблюдаются высокие значения групповых скоростей, указывающие на наличие существенной радиальной анизотропии на больших глубинах в мантии, что, по-видимому, является характерным для центров медленного спрединга [Zhou et al., 2006].

Необходимо отметить, что с увеличением периода вариации скоростей становятся более сглаженными, что свидетельствует о том, что на глубинах более 400 км мантия становится менее дифференцированной по скоростям. 

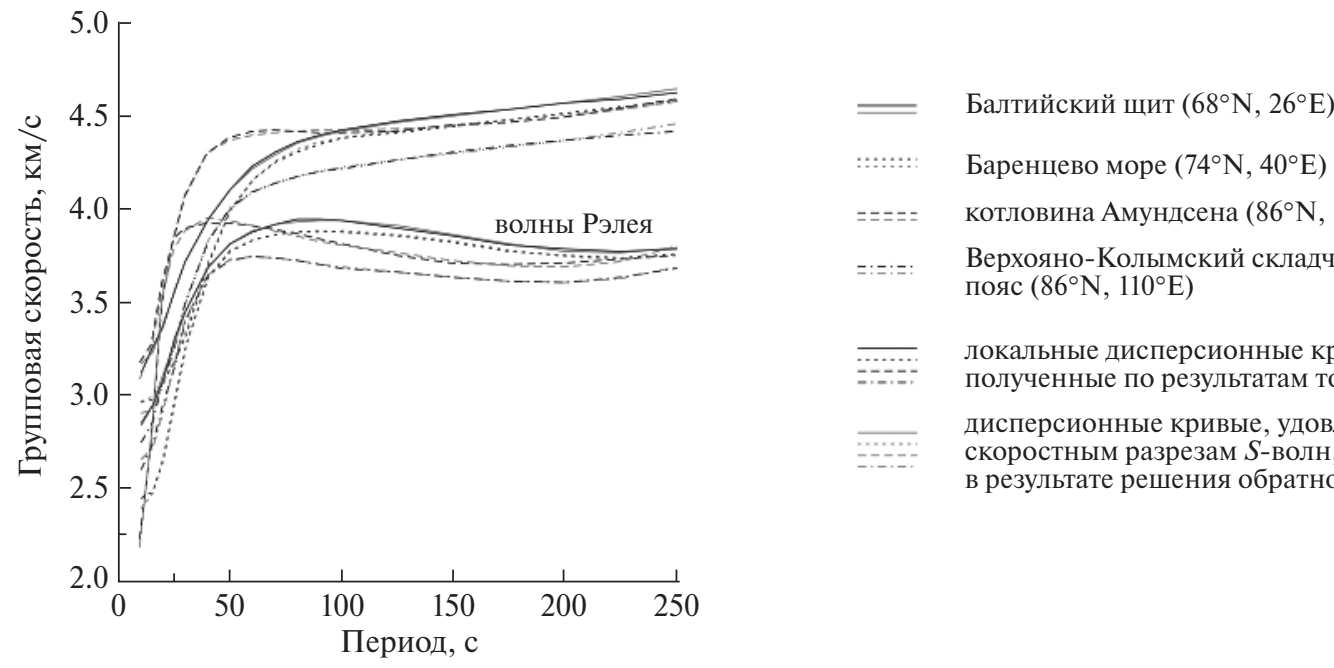

$====$ котловина Амундсена $\left(86^{\circ} \mathrm{N}, 110^{\circ} \mathrm{E}\right)$

-:=:: Верхояно-Колымский складчатый пояс $\left(86^{\circ} \mathrm{N}, 110^{\circ} \mathrm{E}\right)$

локальные дисперсионные кривые, полученные по результатам томографии

дисперсионные кривые, удовлетворяющие скоростным разрезам $S$-волн, полученным в результате решения обратной задачи
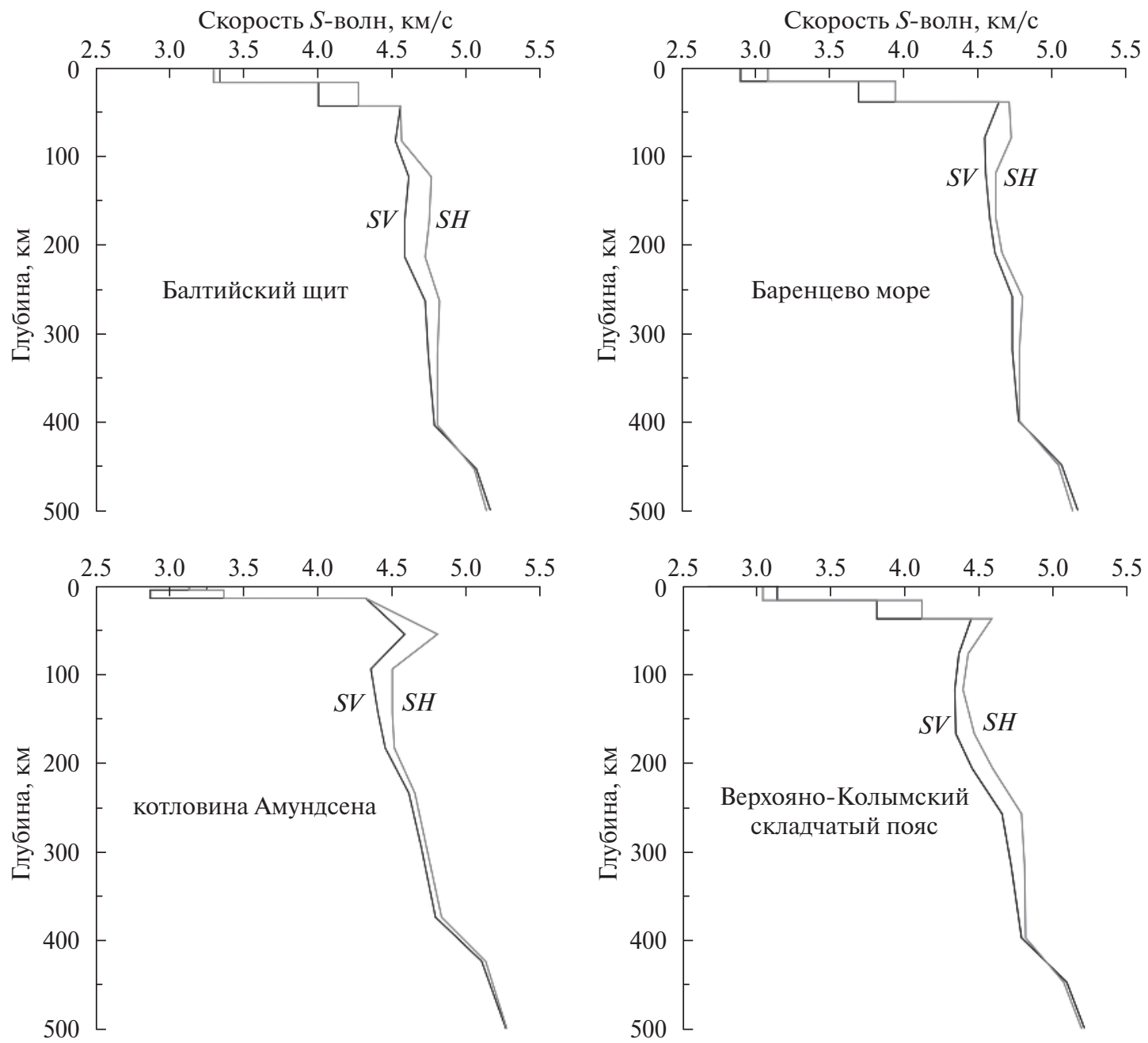

Рис. 9. Дисперсионные кривые волн Рэлея и Лява (а) и соответствующие им скоростные разрезы волн $S V$ и $S H$ (б) для четырех различных в тектоническом отношении регионов Арктики. 


\section{ЗАКЛЮЧЕНИЕ}

На основании проведенного исследования можно заключить, что полученные карты распределений групповых скоростей волн Рэлея и Лява отражают особенности строения коры и верхней мантии Арктики, а выявленные горизонтальные скоростные неоднородности согласуются с геологическим строением области исследования. Полученные карты представляют существенный интерес для дальнейшего построения трехмерной модели распределения скоростей поперечных волн и изучения анизотропных свойств верхней мантии.

Автор выражает глубокую благодарность проф. Т. Б. Яновской (СПбГУ) за предоставленное программное обеспечение, проф. А.Л. Левшину (университет Колорадо, Боулдер, США) и канд. физ.-мат. наук В.М. Кожевникову (ИЗК CO PAH) за ценные консультации и внимание к работе. Работа выполнена при поддержке РНФ, грант № 17-77-10037.

\section{СПИСОК ЛИТЕРАТУРЫ}

Зоненшайн Л.П., Натапов Л.М. Тектоническая история Арктики. Актуальные проблемы тектоники. М.: Наука. 1987. С. 31-57.

Зоненшайн Л.П., Кузьмин М.И., Натапов Л.М. Тектоника литосферных плит территории СССР. М.: Недра. 1990. Кн. 2. 334 c.

Имаева Л.П., Колодезников И.И. (ред.) Сейсмотектоника северо-восточного сектора Российской Арктики. Новосибирск: изд-во СО РАН. 2017. 136 с.

Левшин А.Л., Яновская Т.Б., Ландер А.В., Букчин Б.Г., Бармин М.П., Ратникова Л.И., Итс Е.Н. Поверхностные сейсмические волны в горизонтально-неоднородной Земле. М.: Наука. 1986. 278 с.

Яковлев А.В., Бушенкова Н.А., Кулаков И.Ю., Добрецов Н.Л. Структура верхней мантии Арктического региона по данным региональной сейсмотомографии // Геология и геофизика. 2012. Т. 53. № 10. С. 1261-1272.

Яновская Т.Б. Развитие способов решения задач поверхностно-волновой томографии на основе метода Бэйкуса-Гильберта // Вычислительная сейсмология. Вып. 32 . М.: ГEOC. 2001. C. 11-26.

Яновская Т.Б. Поверхностно-волновая томография в сейсмологических исследованиях. СПб.: Наука. 2015. 167 с.

Allen R.M., Nolet G., Morgan W.J., Vogfjörd K., Nettles M., Ekström G., Bergsson B.H., Erlendsson P., Foulger G.G., Jakobsdóttir S., Julian B.R., Pritchard M., Ragnarsson S., Stefánsson R. Plume-driven plumbing and crustal formation in Iceland // J. Geophys. Res. 2002. V. 107. B8. P. 2163. doi:10.1029/2001 JB000584
Andersen O.B., Knudsen P., Berry P. The DNSC08 GRA global marine gravity field from double retracked satellite altimetry // J. Geodesy 2010. V. 84. № 3. P. 191-199. doi:10.1007/s00190-009-0355-9

Artemieva I. M., Thybo H. EUNAseis: a sesmic model for Moho and crustal structure in Europe, Greenland, and the North Atlantic region // Tectonophysics. 2013. V. 609. P. 97-153. http: // dx.doi.org/10.1016/j.tecto.2013.08.004

Avetisov G.P. Geodynamics of the zone of continental continuation of Mid-Arctic earthquakes belt (Laptev Sea) // Phys. Earth Planet. Inter. 1999. V. 114. P. 59-70.

Bijwaard H., Spakman W., Engdahl E.R. Closing the gap between regional and global travel time tomography // J. Geophys. Res. 1998. V. 103. B12. P. 30055-30078.

Bruneton M., Pedersen H.A., Farra V., Arndt N.T., Vacher P. et al. Complex lithospheric structure under the central Baltic Shield from surface wave tomography // J. Geophys. Res. 2004. V. 109. B10303. doi:10.1029/2003 JB002947

Chen C.-W., Rondenay S., Weeraratne D.S., Snyder D.B. New constraints on the upper mantle structure of the Slave craton from Rayleigh wave inversion // Geophys. Res. Lett. 2007. V. 34. L10301. doi:10.1029/2007 GL029535

Darbyshire F.A. Crustal structure across the Canadian High Arctic region from teleseismic receiver function analysis // Geophys. J. Int. 2003. V. 152. P. 273-391.

Darbyshire F.A., Eaton D.W., Bastow I.D. Seismic imaging of the lithosphere beneath Hudson Bay: episodic growth of the Laurentian mantle keel // Earth Planet. Sci. Lett. 2013. V. 373. P. 179-193. http://dx.doi.org/10.1016/j.epsl.2013.05.002

Darbyshire F.A., Larsen T.B., Mosegaard K., Dahl-Jensen T., Gudmundsson O., Bah T., Gregersen S., Pedersen H.A., Hanka $W$. A first detailed look at the Greenland lithosphere and upper mantle using Rayleigh wave tomography // Geophys. J. Int. 2004. V. 158. P. 267-286. doi:10.1111/j.1365-246 X.2004.02316.x

DeMets C., Gordon R.G., Argus D.F., Stein S. Effect of recent revisions to the geomagnetic reversal time scale on estimates of current plate motions // Geophys. Res. Lett. 1994. V. 21. P. 2191-2194.

Drachev S.S. Fold belts and sedimentary basins of the Eurasian Arctic // Arktos. 2016. V. 2:21.

doi:10.1007/s41063-015-0014-8

Dziewonski A.M., Anderson D.L. Preliminary Reference Earth Model // Phys. Earth Planet. Inter. 1981. V. 25. P. 297-356.

Eksröm $G$. A global model of Love and Rayleigh surface wave dispersion and anisotropy, 25-250s // Geophys. J. Int. 2011. V. 187. P. 1668-1686. doi:10.1111/j.1365-246 X.2011.05225.x Gaina C., Medvedev S., Torsvik T.H., Koulakov I., Werner S.C. 4D Arctic: a glimpse into the structure and evolution of the Arctic in the light of new geophysical maps, plate tectonics and tomographic models // Surv. Geophys. 2014. V. 35. P. 1095-112. doi:10.1007/s10712-013-9254-y

Grad M., Tiira T., Olsson S., Komminaho K. Seismic lithosphere-asthenosphere boundary beneath the Baltic Shield // GFF 2014. V. 00. Pt. 1. P. 1-18. http://dx.doi.org/ 10.1080/11035897.2014.959042 
Gramberg I.S., Verba V.V., Verba M.L., Kos'ko M.K. Sedimentary cover thickness map - sedimentary basins in the Arctic // Polarforschung. 1999. V. 69. P. 243-249.

Jokat W., Schmidt-Aursch M.C. Geophysical characteristics of the ultraslow spreading Gakkel Ridge, Arctic Ocean // Geophys. J. Int. 2007. V. 168. P. 983-998. doi:10.1111/j.1365-246 X.2006.03278.X

Kenyon S., Forsberg R., Coakley B. New gravity field for the Arctic. Eos Trans. AGU 2008. V. 89. 32. P. 289-290. doi:10.1029/2008 EO320002

Kumar P., Kind R., Hanka W., Wylegalla K., Reigber Ch., Yuan X., Woelbern I., Schwintzer P., Fleming K., Dahl-Jensen T., Larsen T.B., Schweitzer J., Priestley K., Gudmundsson O., Wolf $D$. The lithosphere-asthenosphere boundary in the NorthWest Atlantic region // Earth Planet. Sci. Lett. 2005. V. 236. P. 249-257. doi:10.1016/j.epsl.2005.05.029

Laske G., Masters G., Ma Z., Pasyanos, M. Update on CRUST1.0 - A 1-degree Global Model of Earth's Crust // Geophys. Res. Abstracts. 15. Abstract EGU 2013-2658. 2013.

Lebedeva-Ivanova N.N., Zamansky Y.Ya., Langinen A.E. Seismic profiling across the Mendeleev Ridge at $82^{\circ} \mathrm{N}$ : evidence of continental crust // Geophys. J. Int. 2006. V. 165. P. 527-544. doi:10.1111/j.1365-246 X.2006.02859.X

Levshin A.L., Schweitzer J., Weidle C., Shapiro N.M., Ritzwoller M.H. Surface wave tomography of the Barents Sea and surrounding regions // Geophys. J. Int. 2007. V. 170. P. 441-459. doi:10.1111/j.1365-246 X.2006.03285.x

Levshin A.L., Ritzwoller M.H., Barmin M.P., Villasenor A., Padgett C.A. New constraints on the arctic crust and uppermost mantle: surface wave group velocities, Pn, and Sn // Phys. Earth Planet. Inter. 2001. V. 123. P. 185-204.

Olsson S., Roberts R.G., Böðvarsson R. Analysis of waves converted from $\mathrm{S}$ to $\mathrm{P}$ in the upper mantle beneath the Baltic Shield // Earth Planet. Sci. Lett. 2007. V. 257. P. 37-46.

Pedersen H.A., Debayle E., Maupin V. et al. Strong lateral variations of lithospheric mantle beneath cratons - example from the Baltic shield // Earth Planet. Sci. Lett. 2013. V. 383. P. 164-172. http://dx.doi.org/10.1016/j.epsl.2013.09.024

Pilidou S., Priestley K., Gudmundsson O., Debayle E. Upper mantle S-wave speed heterogeneity beneath the North Atlantic from regional surface wave tomography: the Iceland and Azores plumes // Geophys. J. Int. 2004. V. 159. P. 10571076. doi:10.1111/j.1365-246 X.2004.02462.x
Pilidou S., Priestley K., Debayle E., Gudmundsson O. Rayleigh wave tomography in the North Atlantic: high resolution images of the Iceland, Azores and Eifel mantle plumes // Lithos. 2005. V. 79. P. 453-474. doi:10.1016/j.lithos.2004.09.012

Rickers F., Fichter A., Trampert J. The Iceland-Jan Mayen plume system and its impact on mantle dynamics in the North Atlantic region: evidence from full-waveform inversion // Earth Planet. Sci. Lett. 2013. V. 367. P. 39-51. http://dx.doi.org/10.1016/j.eps1.2013.02.022

Ritzwoller M.H., Levshin A.L. Eurasian surface wave tomography: group velocities // J. Geophys. Res. 1998. V. 103. P. 4839-4878.

Schaeffer A.J., Lebedev S. Global shear speed structure of the upper mantle and transition zone // Geophys. J. Int. 2013. V. 194. P. 417-449. doi: 10.1093/gji/ggt095

Schilling J.G., Kingsley R., Fontignie D., Poreda R., Xue S. Dispersion of the Jan Mayen and Iceland mantle plumes in the Arctic: a $\mathrm{He}-\mathrm{Pb}-\mathrm{Nd}-\mathrm{Sr}$ isotope tracer study of basalts from the Kolbeinsey, Mohns and Knipovich Ridges // J. Geophys. Res. 1999. V. 10. 5. P. 10543-10569.

Shapiro N.M., Ritzwoller M.H. Monte-Carlo inversion for a global shear-velocity model of the crust and upper mantle // Geophys. J. Int. 2002. V. 151. P. 88-105.

Verhoef J., Roest W.R., Macnab R., Arkani-Hamed J. Project Team Magnetic anomalies of the Arctic and North Atlantic Oceans and adjacent land areas. Geological Survey of Canada 1996. Open File 3125 a.

Yanovskaya T.B., Antonova L.M., Kozhevnikov V.M. Lateral variations of the upper mantle structure in Eurasia from group velocities of surface waves // Phys. Earth Planet. Inter. 2000. V. 122. P. 19-32.

Yanovskaya T.B., Kozhevnikov V.M. 3D S-wave velocity pattern in the upper mantle beneath the continent of Asia from Rayleigh wave data // Phys. Earth Planet. Inter. 2003. V. 138. P. 263-278.

Zhou Y., Nolet G., Dahlen F.A., Laske G. Global uppermantle structure from finite-frequency surface-wave tomography // J. Geophys. Res. 2006. V. 111. B04304. doi:10.1029/2005 JB003677 


\title{
Surface Wave Tomography of the Arctic from Seismic Rayleigh and Love Wave Group Velocity Dispersion Data
}

\author{
A. I. Seredkina ${ }^{a, b *}$ \\ ${ }^{a}$ Institute of the Earth's Crust, Siberian Branch, Russian Academy of Sciences, Irkutsk, 664033 Russia \\ ${ }^{b}$ Institute of Terrestrial Magnetism, Ionosphere and Radio Wave Propagation, Russian Academy of Sciences, \\ Troitsk, Moscow, 108840 Russia \\ *E-mail: ale@crust.irk.ru \\ Received December 11, 2017
}

The results of studying the deep structure of the Earth's crust and upper mantle of the Arctic from surface wave data are presented. For this purpose, based on the frequency-time analysis procedure, a representative dataset of group velocity dispersion curves of seismic Rayleigh and Love waves (1555 and 1265 paths, respectively) in the period range from 10 to $250 \mathrm{~s}$ is obtained. With the use of a two-dimensional tomography technique for a spherical surface, group velocity distributions are calculated at separate periods. Overall, 18 maps for each type of surface waves are constructed and the horizontal resolution of the mapping is estimated. For four tectonically different regions of the Arctic, the dispersion curves calculated from the tomography results are inverted for the velocity sections of the $S V$ - and $S H$-waves. Based on the obtained distributions, the main large-scale features are analyzed in the deep structure of the Earth's crust and upper mantle of the Arctic, and the revealed velocity irregularities are correlated to various geological structures. The results of the study are of considerable interest for further constructing the three-dimensional model of the shear wave velocity distributions and for studying the anisotropic properties of the upper mantle of the Arctic, as well as for building the geodynamical models of the region.

Keywords: surface wave tomography, group velocities, Rayleigh and Love waves, upper mantle, Arctic 